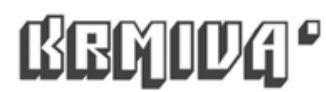

\author{
UTJECAJ KONVEKCIJSKOG SUŠENJA NA SADRŽAJ ŠKROBA I PEPELA \\ RAZLIČITIH SORATA BATATA
}

\section{CONVECTIVE DRYING IMPACT ON STARCH AND ASH CONTENT OF DIFFERENT SWEET POTATO VARIETIES} Ana Matin, Tajana Krička, Sanja Kalambura, Vanja Jurišić, Marija Livaić, B.
Benko, Mateja Grubor

Izvorni znanstveni članak - Original scientific paper
Primlieno - Received: 15. Prosinac - December 2017

\section{SAŽETAK}

Batat (Ipomoea batatas L.) je višegodišnja tropska povrtna kultura koja se koristi u hranidbi domaćih životinja (krava, svinja i peradi), a porasla mu je i konzumacija u ljudskoj prehrani posljednjih nekoliko godina. Cilj istraživanja ovog rada je utvrditi sadržaj pepela i škroba batata, radi probavljivosti, nakon konvekcijskog sušenja - dehidriranjem na tri različite temperature sušenja ( 50 , 60 i $70^{\circ} \mathrm{C}$ ), brzinu otpuštanja vode prilikom sušenja kao i utjecaj temperature sušenja na boju četiriju sorata batata (narančasti Beauregard, ljubičasti 414 Purple, žuti O'Henry i bijeli Japanese). Rezultati istraživanja pokazuju da od četiri istraživane sorte samo jedna brže otpušta vodu prilikom sušenja, dok sve ostale otpuštaju vodu podjednakom brzinom. Kod toga je sadržaj pepela rastao povećanjem temperature dok se sadržaj škroba smanjivao. Također je utvrđeno da sušenje utječe na promjenu boje, te se najmanja promjena očekivano očitovala sušenjem na najnižoj temperaturi. Statističkom obradom rezultata utvrđene su signifikantne razlike između sorata i načina termičke dorade.

Ključne riječi: batat, sušenje, kvalitativne karakteristike, promjena boje

\section{UVOD}

Batat (Ipomoea batatas L.) je višegodišnja tropska povrtna kultura iz porodice slakova (Convolvuaceae). Uzgaja se u tropskom i suptropskom klimatskom području, a potječe iz središnjeg dijela Južne Amerike, odakle se u 16 st. proširio na Europu, Afriku i Aziju. Visoko je enegetska kultura bogata škrobom i biološki aktivnim tvarima poput $\beta$-karotena, polifenola, askorbinske kiseline i dijetalnih vlakana (Van Hal, 2000.). Jednako tako sadrži vitamine E, B1, B2 i B3 te Fe, K, Ca, Zn, Na, Mg i Mn (Adebowale i sur., 2005.; Woolfe, 1992.).
U prehrani se koriste sekundarna zadebljanja korijena (koja se često pogrešno nazivaju gomoljima), kao i mlado lišće. Prije upotrebe korijen i lišće potrebno je termički doraditi (Bovell-Benzamin, 2007.). Batat se može dorađivati različitim termičkim postupcima (kuhanjem, pečenjem, sušenjem) (BovellBenzamin, 2007.).

Mogućnosti korištenja batata u raznim prehrambenim proizvodima konditorske industrije istraživali su Palomar i sur.(1994.), Pangloli i sur. (2000.), Montreka i Adelia (2003.), Chen i sur. (2003.), Yadav i sur. (2006.), gdje su utvrdili, između ostalog, da batat

doc. dr. sc. Ana Matin, e-mail: amatin@agr.hr, prof. dr. sc. Tajana Krička, doc. dr. sc. Vanja Jurišić, Marija Livaić, mag. ing. agr. Mateja Grubor, mag. ing. agr., Zavod za poljoprivrednu tehnologiju, skladištenje i transport; izv. prof.. dr. sc. Božidar Benko, Zavod za povrćarstvo, Sveučilište u Zagrebu Agronomski fakultet, Svetošimunska cesta 25, 10000 Zagreb, izv. prof. dr. sc. Sanja Kalambura, Veleučilište Velika Gorica, Zagrebačka 5, 10410 Velika Gorica 
u sebi sadrži visoki sadržaj vode koja utječe na okus, izgled i strukturu hrane, ali i na njezinu podložnost kvarenju.

Osim za ljudsku prehranu, batat se koristi i u hranidbi domaćih životinja i to prije svega krava, svinja i peradi. U hranidbi svinja ubrzava tov i time povećava prinos mesnih jedinica. Kod krava u čijem se obroku nalazi batat primijećeno je da daju veće količine mlijeka, dok kokoši daju veći broj jaja, uz bolju pigmentaciju. Pozitivni efekti su primijećeni i kod uzgoja broilera, posebice nakon osam tjedana kada dobivaju značajni prirast mase (Loebenstein, 2009.).

Kao jedan od načina termičke dorade batata je konvekcijsko sušenje dehidriranjem uz primjenu zagrijanog zraka kao medija. Kod ovog načina sušenja prijenos topline ovisi o svojstvima zagrijanog zraka kao što su temperatura, vlažnost, brzina strujanja i tlak (Okos i sur., 2007.). Tomas (2000.) i Sokele (1998.) navode kako bi se neki materijal osušio mora se zagrijati do temperature na kojoj je parcijalni tlak vodene pare na površini sušenog materijala veći od tlaka zraka.

$U$ periodu konstantne brzine sušenja vlažna površina materijala ima temperaturu koja odgovara temperaturi mokrog termometra zraka kojim se suši, dok se u periodu padajuće brzine sušenja temperatura materijala približava temperaturi suhog termometra medija kojim se provodi sušenje (Niketić-Aleksić, 1988.). Ako se povisi temperatura zraka kojom se suši, sušenje se odvija brže, ali kod toga se mora paziti na temperaturu materijala koji se suši (Krička i Pliestić, 1994.; Krička i sur., 2007.), poglavito kada se suše materijali osjetljivi na povišene temperature, kao što su prehrambeni ili sjemenski materijali (Ježek, 1999.; Sander, 2003.; Matin i sur., 2016.; Tomas, 2000.).

Općenito, utvrđeno je da sušenje vrućim zrakom može uzrokovati smanjenje kvalitativnih svojstava koja podrazumijevaju nutritivne vrijednosti, boju i druga organoleptička svojstva (Krokida i sur.,1998.; McMinn i Magee, 1996.; Wang i Brennan, 1995.). Dehidrirani batat obično se dobiva sušenjem vrućim zrakom, što omogućuje tretman, iako u velikoj mjeri utječe na senzorske i prehrambene karakteristike krajnjeg proizvoda (Akyildiz i sur., 2004.; Dewanto i sur., 2002.). Zbog navedenog važno je istražiti mogućnosti očuvanja proizvoda te načine konzerviranja. Slično su istraživanje sušenja batata proveli i Olawale i Omole (2012.). Osim za potrebe skladištenja, batat se dorađuje i s ciljem povećanja njegove probavljivosti u hranidbi životinja, jer je škrob bogat izvor energije (Svihus i sur., 2005.). Zbog toga je važno poznavati njegovo ponašanje, kako u probavnom sustavu životinja, tako i prilikom različitih tehnoloških procesa: mljevenja, kondicioniranja, ekstrudiranja, peletiranja, sušenja i hlađenja.

Temeljem svega navedenog cilj ovog rada je utvrditi utjecaj temperature zraka konvekcijskim sušenjem - dehidriranjem $\left(50{ }^{\circ} \mathrm{C}, 60^{\circ} \mathrm{C} \mathrm{i} 70^{\circ} \mathrm{C}\right)$ na kvalitativna svojstva, brzinu otpuštanja vode te promjenu boje četiriju sorta batata (narančasti Beauregard, ljubičasti 414 Purple, žuti O'Henry i bijeli Japanese).

\section{MATERIJALI I METODE}

Istraživanje je provedeno u Laboratoriju Zavoda za poljoprivrednu tehnologiju, skladištenje i transport na Agronomskom fakultetu Sveučilištu u Zagrebu na četiri sorte batata (Ipomoea batatas L.) različitih prema boji mesa (narančasto, žuto, ljubičasto i bijelo). U istraživanju su korištene sorte Beauregard (narančasto meso), O'Henry (žuto meso), 414 Purple (ljubičasto meso) i Japanese (bijelo meso). Batat je uzgojen u Republici Hrvatskoj u 2016. godini. Sve provedene analize rađene su netom nakon berbe, najprije na prirodnim uzorcima,a zatim na uzorcima sušenim s tri različite temperature.

Konvekcijsko sušenje je provedeno u dehidratoru (Exaliburdehydrator 4926T, USA) s temperaturama zraka za sušenje od 50,60 i $70^{\circ} \mathrm{C}$ do vlažnosti od $9 \%$. Brzina zraka prilikom sušenja bila je održavana na $0,5 \mathrm{~m} \mathrm{~s}^{-1}$. Gubitak vlažnosti izračunat je na osnovi izmjerenih podataka o gubitku mase svakih 30 minuta.

Prema standardnim metodama određen je sadržaj vode u laboratorijskoj sušnici (INKO ST-40, Hrvatska) (HRN ISO 6540:2010), pepela u mufolnoj peći Nabertherm B170 (Lilienthal, Njemačka) (HRN ISO 2171:2010), škroba na polarimetru (KRÜSS, P3001, Njemačka) (HRN ISO 6493:2001) te promjena boje pomoću kolorimetra (Colortec PMC) po CIE LAB sustavu boja. 
Nakon prikupljanja podataka laboratorijskih istraživanja, provela se statistička obrada dobivenih podataka pomoću statističkog programskog paketa SAS verzije 9.3 (SAS Institute, Cary, NC, USA) uz uporabu GLM procedure i Tukey-evog testa višestrukih usporedbi uz nivo značajnosti $\mathrm{P} \geq 0.05$.

\section{REZULTATI I RASPRAVA}

Početne vlažnosti batata kretale su se od $82,56 \%$ kod sorte 414 Purple do $88,55 \%$ kod sorte Japanese. Brzina otpuštanja vode podrazumijeva promjenu sadržaja vode i temperature batata tijekom sušenja i prikazana je krivuljama otpuštanja vode do ravnotežne vlažnosti (slike od 1 do 3).

Analizom tablice 1 vidi se da sorta 414 Purple najbrže otpušta vodu na svim temperaturama, dok sve ostale sorte podjednako otpuštaju vodu na svim temperaturama. Kod svih istraživanih eksponencijalnih jednadžbi utvrđen je koeficijent determinacije $R^{2}$ (tablica 1) od 0,929 do 0,993 što pokazuje da su rezultati međusobno usporedivi. Slične vrijednosti koeficijenta determinacije prilikom sušenja batata dobili su Singh i Pandey (2012.).
U tablici 2 prikazani su sadržaj pepela i škroba prirodnog batata, kao i batata nakon sušenja.

Prema rezultatima iz tablice 2 nakon termičke dorade vrijednost sadržaja vode i škroba signifikantno pada, dok sadržaj pepela signifikantno raste kod svih istraživanih sorata. S nutritivnog aspekta sadržaj pepela je loše svojstvo, a sadržaj škroba dobro u ovisnosti o zahtjevima. Međusobnom usporedbom vrijednosti, uočeno je kako početni uzorak sorte 414 Purple sadrži signifikantno najveći sadržaj pepela (1,75\%), a sorta Japanese najmanji $(1,16 \%)$ što potvrđuje i navod Ukom-a i sur. (2009.) koji navodi sadržaj pepela kod bijele sorte batata od 1,3 do $1,7 \%$, narančaste sorte od 1,4 do $1,7 \%$. Jednako tako i Van Hal (2000.) u provedenom istraživanju navodi sadržaj pepela sličnih vrijednosti. Međusobnom usporedbom vrijednosti sadržaja škroba prirodnog uzorka uočeno je kako batat sorte 414 Purple sadrži veći sadržaj škroba $(62,31 \%)$ nego batat sorte Bauregard (59,02\%). Najmanju vrijednost udjela škroba u prirodnom uzorku sadrži batat sorte Japanese $(58,25 \%)$.

Tablica 1. Eksponencijalne jednadžbe otpuštanja vode iz mesa četiriju sorta batata

Table 1 Water release equations from sweet potato

\begin{tabular}{|c|c|c|}
\hline $\begin{array}{l}\text { Sorta } \\
\text { Variety }\end{array}$ & $\begin{array}{l}\text { Jednadžba otpuštanja vode } \\
\text { Water release equations }\end{array}$ & $\begin{array}{l}\text { Koeficijent determinacije } \\
\text { Determination coefficient } \mathrm{R}^{2}\end{array}$ \\
\hline \multicolumn{3}{|c|}{$50^{\circ} \mathrm{C}$} \\
\hline Bauregard & $y=73,275$ & 0,964 \\
\hline 414 Purple & $y=71,075$ & 0,966 \\
\hline O'Henry & $y=76,349$ & 0,967 \\
\hline Japanese & $y=84,289$ & 0,993 \\
\hline \multicolumn{3}{|c|}{$60^{\circ} \mathrm{C}$} \\
\hline Bauregard & $y=72,522$ & 0,962 \\
\hline 414 Purple & $y=70,269$ & 0,972 \\
\hline O'Henry & $y=75,823$ & 0,977 \\
\hline Japanese & $y=83,993$ & 0,993 \\
\hline \multicolumn{3}{|c|}{$70^{\circ} \mathrm{C}$} \\
\hline Bauregard & $y=71,242$ & 0,943 \\
\hline 414 Purple & $y=67,511$ & 0,929 \\
\hline O'Henry & $y=74,629$ & 0,962 \\
\hline Japanese & $y=81,094$ & 0,979 \\
\hline
\end{tabular}

Legenda: $y$ = količina vode $(\%), x=$ vrijeme $(\mathrm{min}), \mathrm{R}^{2}=$ koeficijent determinacije

Legend: $y=$ water quantity $(\%), x=$ time $(\mathrm{min}), \mathrm{R}^{2}=$ determination coefficient 
Tablica 2. Sadržaj vode, pepela i škroba u prirodnim i sušenim uzorcima batata

Table 2 Water, ash and starch content of natural and dried samples of sweet potato

\begin{tabular}{|c|c|c|c|c|}
\hline $\begin{array}{l}\text { Sorta } \\
\text { Variety }\end{array}$ & $\begin{array}{l}\text { Tretman } \\
\text { Treatment }\end{array}$ & $\begin{array}{c}\text { Voda } \\
\text { Water (\%) }\end{array}$ & $\begin{array}{c}\text { Pepeo } \\
\text { Ash (\%) }\end{array}$ & $\begin{array}{c}\text { Škrob } \\
\text { Starch (\%) }\end{array}$ \\
\hline \multirow{4}{*}{$\begin{array}{l}\text { Bauregard } \\
\text { (narančasta boja / } \\
\text { orange color) }\end{array}$} & $--^{*}$ & $85,04^{a} \pm 0,62$ & $1,46^{d} \pm 0,01$ & $59,02^{a} \pm 0,07$ \\
\hline & $50^{\circ} \mathrm{C}$ & $9,60^{\mathrm{b}} \pm 0,10$ & $5,85^{a} \pm 0,06$ & $47,88^{b} \pm 0,21$ \\
\hline & $60^{\circ} \mathrm{C}$ & $9,45^{b c} \pm 0,08$ & $4,49^{b} \pm 0,08$ & $48,36^{b} \pm 0,18$ \\
\hline & $70^{\circ} \mathrm{C}$ & $9,32^{\mathrm{c}} \pm 0,08$ & $3,80^{\circ} \pm 0,04$ & $49,52^{b} \pm 0,14$ \\
\hline \multirow{4}{*}{$\begin{array}{l}414 \text { Purple } \\
\text { (ljubičasta boja / } \\
\text { purple color ) }\end{array}$} & - & $82,56^{a} \pm 0,58$ & $1,75^{d} \pm 0,02$ & $62,31^{a} \pm 0,12$ \\
\hline & $50^{\circ} \mathrm{C}$ & $9,57^{b} \pm 0,06$ & $6,92^{\mathrm{a}} \pm 0,12$ & $54,06^{b} \pm 0,16$ \\
\hline & $60^{\circ} \mathrm{C}$ & $9,38^{\mathrm{bc}} \pm 0,09$ & $5,84^{b} \pm 0,08$ & $54,75^{b} \pm 0,20$ \\
\hline & $70^{\circ} \mathrm{C}$ & $9,02^{\mathrm{c}} \pm 0,07$ & $4,34^{c} \pm 0,04$ & $55,47^{b} \pm 0,22$ \\
\hline \multirow{4}{*}{$\begin{array}{l}\text { O’Henry } \\
\text { (žuta boja / } \\
\text { yellow color) }\end{array}$} & - & $85,32^{a} \pm 0,64$ & $1,25^{\circ} \pm 0,02$ & $59,61^{a} \pm 0,10$ \\
\hline & $50^{\circ} \mathrm{C}$ & $9,73^{b} \pm 0,04$ & $4,49^{a} \pm 0,07$ & $42,87^{b} \pm 0,23$ \\
\hline & $60^{\circ} \mathrm{C}$ & $9,52^{\mathrm{c}} \pm 0,06$ & $3,98^{b} \pm 0,04$ & $43,79^{b} \pm 0,21$ \\
\hline & $70^{\circ} \mathrm{C}$ & $9,41^{\mathrm{c}} \pm 0,06$ & $3,90^{\mathrm{b}} \pm 0,05$ & $44,67^{b} \pm 0,26$ \\
\hline \multirow{4}{*}{$\begin{array}{l}\text { Japanese } \\
\text { (bijela boja / } \\
\text { white color) }\end{array}$} & - & $88,55^{a} \pm 0,56$ & $1,16^{\mathrm{d}} \pm 0,01$ & $58,25^{a} \pm 0,06$ \\
\hline & $50^{\circ} \mathrm{C}$ & $9,94^{b} \pm 0,08$ & $4,33^{a} \pm 0,06$ & $37,92^{b} \pm 0,20$ \\
\hline & $60^{\circ} \mathrm{C}$ & $9,65^{b c} \pm 0,09$ & $3,79^{b} \pm 0,07$ & $38,75^{b} \pm 0,31$ \\
\hline & $70^{\circ} \mathrm{C}$ & $9,56^{c} \pm 0,09$ & $3,09^{c} \pm 0,02$ & $40,19^{b} \pm 0,26$ \\
\hline
\end{tabular}

" "-" bez tretmana / without treatment

Srednje vrijednosti $\pm S D$, $s$ istim slovom nisu signifikantno različite $(p<0,05)$ prema Tukey-evom HSD testu

The mean values \pm SD, with the same letter are not significantly different $(p<0.05)$ according to Tukey's HSD test

Tablica 3. Vrijednost koeficijenta obojenja batata u prirodnom i sušenom uzorku

Table 3 Value of color coefficient in natural and dried sample of sweet potato

\begin{tabular}{|c|c|c|c|c|c|c|}
\hline $\begin{array}{c}\text { Sorta } \\
\text { Variety }\end{array}$ & $\begin{array}{c}\text { Tretman } \\
\text { Treatment }\end{array}$ & $L$ & A & $b$ & C & C \\
\hline \multirow{4}{*}{$\begin{array}{l}\text { Bauregard } \\
\text { (narančasta boja / } \\
\text { orange color) }\end{array}$} & $-^{*}$ & 66,88 & 19,34 & 37,86 & 903,65 & 42,51 \\
\hline & $50^{\circ} \mathrm{C}$ & 64,60 & 18,27 & 36,80 & 844,02 & 41,09 \\
\hline & $60^{\circ} \mathrm{C}$ & 57,37 & 13,41 & 34,44 & 682,27 & 36,96 \\
\hline & $70^{\circ} \mathrm{C}$ & 56,86 & 11,47 & 27,00 & 430,28 & 29,33 \\
\hline \multirow{4}{*}{$\begin{array}{l}414 \text { Purple } \\
\text { (ljubičasta boja / } \\
\text { purple color ) }\end{array}$} & - & 35,93 & 21,38 & 1,61 & 229,85 & 21,44 \\
\hline & $50^{\circ} \mathrm{C}$ & 39,75 & 9,53 & 1,72 & 46,89 & 9,68 \\
\hline & $60^{\circ} \mathrm{C}$ & 40,45 & 8,92 & 5,65 & 55,74 & 10,56 \\
\hline & $70^{\circ} \mathrm{C}$ & 50,74 & 4,65 & 7,53 & 39,16 & 8,85 \\
\hline \multirow{4}{*}{$\begin{array}{l}\text { O’Henry } \\
\text { (žuta boja / } \\
\text { yellow color) }\end{array}$} & - & 78,89 & $-6,14$ & 8,09 & 51,57 & 10,16 \\
\hline & $50^{\circ} \mathrm{C}$ & 78,57 & $-6,29$ & 11,77 & 89,05 & 13,35 \\
\hline & $60^{\circ} \mathrm{C}$ & 71,98 & $-5,32$ & 12,61 & 93,66 & 13,69 \\
\hline & $70^{\circ} \mathrm{C}$ & 64,64 & $-4,03$ & 13,76 & 102,79 & 14,34 \\
\hline \multirow{4}{*}{$\begin{array}{l}\text { Japanese } \\
\text { (bijela boja / } \\
\text { white color) }\end{array}$} & - & 77,89 & $-3,93$ & 7,90 & 38,93 & 8,82 \\
\hline & $50^{\circ} \mathrm{C}$ & 70,85 & $-4,31$ & 10,69 & 66,43 & 11,53 \\
\hline & $60^{\circ} \mathrm{C}$ & 64,77 & $-8,76$ & 11,04 & 99,31 & 14,09 \\
\hline & $70^{\circ} \mathrm{C}$ & 65,67 & $-9,87$ & 13,51 & 139,97 & 16,73 \\
\hline
\end{tabular}

Legenda: $L=$ koeficijent obojenosti, $A=$ komponenta odnosa zeleno/crvena, $b=$ žuto/plava komponenta, $C=$ intenzitet boje, $c=$ zasićenost boje Legend: $\mathrm{L}=$ coloring coefficient, $\mathrm{A}=$ component relations green/red, $\mathrm{b}=$ yellow/blue component, $\mathrm{C}=\mathrm{color}$ intensity, $\mathrm{C}=$ color saturation

* "-" bez tretmana / without treatment 
U tablici 3 prikazane su vrijednosti obojenja svih četiriju sorta batata.

Temeljem dobivenih rezultata $u$ tablici 3 je vidljivo kako je došlo do promjene, tijekom termičke dorade, u obojenosti svih četiriju sorata promjenom L vrijednosti. Jedino kod sorte ljubičaste boje, odnosno 414 Purple, vrijednost koeficijenta obojenja (L) je rasla povišenjem temperature sušenja. Najveću prisutnost crvene boje (vrijednost A) pokazuje narančasta sorta Bauregard i nešto nižu prisutnost ljubičasta sorta 414 , a povećavanjem temperature sušenja prisutnost crvene boje smanjuje se kod svih sorata. Sorte žute (O'Henry) i bijele (Japanese) boje pokazuju negativnu A vrijednost što ukazuje na prisutnost zelene boje. Sve istraživane sorte na svim temperaturama sušenja, kao i prirodni uzorci, pokazuju pozitivnu vrijednost (b), odnosno prisutnost žute boje koja se najviše ističe u sorti žute O'Henry i bijele boje Japanese i povećava se na višim temperaturama sušenja. Najveću zasićenost boje (c) pokazuju sorte narančaste i ljubičaste boje mesa i to $u$ prirodnim uzorcima. Naime, korelacija između porasta temperature sušenja i promjene boje $L, A, C$ postoji kod svih istraživanih sorata.

Prema istraživanju Shiha i sur., (2009.) promjena boje batata bila je veća kod žutog batata nego kod narančastog u procesu sušenja, dok su Ameny i Wilson, 1997 utvrdili da se intenzitet boje razlikuje unutar sorata, te varira od bijele do naranče, a intenzitet narančaste boje pripisuje se sadržaju karotenoida. Krokida i sur., (2001.) istražili su učinke metoda sušenja na boju sušenog batata i utvrdili da je konvekcijsko sušenje zrakom uzrokovalo opsežno zatamnjenje mesa uz značajan pad svjetlosti i povećanje crvenila i žutih mrlja osušenog batata.

\section{ZAKLJUČAK}

$\mathrm{Na}$ osnovi rezultata istraživanja provedenih u ovom radu može se zaključiti da se konvekcijsko sušenje - dehidriranjem četiriju sorata batata na temperaturama od $50^{\circ} \mathrm{C}, 60^{\circ} \mathrm{C}$ i $70^{\circ} \mathrm{C}$ pokazalo odgovarajućom metodom sušenja te uspješno za otpuštanje vode prilikom sušenja. Navedeno potvrđuje statistička analiza eksperimentalnih podataka s visokim vrijednostima koeficijenta determinacije $\left(\mathrm{R}^{2}\right)$ koje se kreću u intervalu 0,929-0,993. Sorta 414
Purple najbrže je otpuštala vodu na svim temperaturama, dok su sve ostale podjednako otpuštale vodu. Temperatura sušenja od $70{ }^{\circ} \mathrm{C}$ pokazala se kao optimalna temperatura sušenja batata za sve sorte vezano uz sadržaj pepela i škroba, kao značajnih komponenti probavljivosti u hranidbi, dok se temperatura sušenja od $50{ }^{\circ} \mathrm{C}$ pokazala kao najoptimalnija prilikom praćenja promjene boje. Kao najkvalitetnija sorta glede sadržaja pepela i škroba pokazala se sorta 414 Purple, ljubičaste boje mesa.

\section{LITERATURA}

1. Adebowale, A.A.; Sanni L.O.; Aownorin, S.O. (2005.): Effect of texture modifiers on the physicochemical and sensory properties of dried fufu. Food Sci. Technol. Int., 11: 373-382.

2. Akyıldız, A.; Aksay, S.; Benli, H.; Kıroğlu, F.; Fenercioğlu, H. (2004.): Determination of changes in some characteristics of persimmon during dehydration at different temperatures. Journal of food engineering, 65(1), 95-99.

3. Ameny, M.A.; Wilson, P.W. (1997.): Relationship between Hunter color values and B-carotene contents in white-fleshed African sweet potatoes (Ipomoea batatas Lam). J. Sci. FoodAgric. 73, 301-306

4. Bovell-Benjamin, A. C. (2007.): Sweet potato: A review of its past, present, and future role in human nutrition. Adv. Food Nutr. Res. 52:1-59.

5. Chen, Z.; Schols, H.A.; Voragen, A.G.J. (2003.): Physico chemical properties of starches obtained from three varieties of Chinese sweet potatoes. Journal of Food Science, 68(2), 431-437

6. Dewanto, V.: Wu, X.; Adom, K.K.; Liu, R.H. (2002.): Thermal processing enhances the nutritional value of tomatoes by increasing total antioxidant activity. Journal of agricultural and food chemistry, 50(10), 3010-3014.

7. HRN EN ISO 2171:2010 (2010.): Determination of ash yield by incineration. Croatian Standards Institute.

8. HRN EN ISO 6540:2010 (2010.): Determination of moisture content. Croatian Standards Institute.

9. HRN ISO 6493:2001 (2001.): Determination of starch content -- Polarimetric method. Croatian Standards Institute

10. Ježek, D. (1999.): Prijelaz topline između uronjenog orebrenog grijača i sloja čestica prehrambenih proizvoda različitih dimenzija. Disertacija. Prehrambenobiotehnološki fakultet, Zagreb, 3- 68. 
11. Krokida, M.K.; Maroulis, Z.B.; Saravacos, G.D. (2001.): The effect of the method of drying on the colour of dehydrated products. International journal of food science technology, 36(1), 53-59

12. Loebenstein, G. (2009.): Origin, distribution and economic importance. In The sweet potato Springer, Dordrecht. 9-12.

13. Matin, A.; Krička, T.; Jurišić, V.; Voća, N.; Antonović, A.; Bilandžija, N.; Miličević, I. (2016): Iskoristivost biomase kukuruza za proizvodnju toplinske energije. In Proceedings. 51st Croatian and 11th International Symposium on Agriculture. Opatija. Croatia .Vol. 489-492.

14. McMinn, W.A.M.; Magee, T.R.A. (2003.): Thermodynamic properties of moisture sorption of potato. Journal of food engineering, 60 (2), 157-165.

15. Montreka, Y.D.; Adelia C.B.B. (2003.): Production and Proximate composition of a hydroponic sweet potato flour during extended storage. Journal of Food Processing and Preservation, 27. 153-164.

16. Niketić-Aleksić, G. (1988.): Tehnologija voća i povrća, Naučna knjiga, Poljoprivredni fakultet, Beograd, str. 283.

17. Okos, M.R.; Campanella, O.; Narsimhan, G.; Singh, R.K.; Weitnauer, A.C. (2007.): Food Dehydration. U Handbook of food engineering 2nd edition, Heldman D R, Lund D B (ed), 601-745. CRC Press Taylor \& Francis Group, Boca Raton, str. 58.

18. Olawale,A. S.; Omole, S. O. (2012.): Thin layer drying models for sweet potato in tray dryer. Agric Eng Int: CIGR Journal, 14 (2).

19. Palomar, L.S.; Galvez, F.C.F.; Resurreccion, A.V.A.; Beuchat, L.R. (1994.):Optimization of a peanutsweet potato cookie formulation. LWT-Food Scienceand Technology, 27 (4), 314-318.

20. Pangloli, P.; Collins, J.L.; Penfield, M.P. (2000.): Storage conditions affect quality of noodles with added soy flour and sweet potato. International journal of food science \& technology, 35(2), 235-242.
21. Sander, A. (2003.): Komparativna istraživanja kinetike sušenja čvrstih materijala. Disertacija. Fakultet kemijskog inženjerstva i tehnologije, Zagreb, 3-40.

22. SAS 9.3: SAS Institute Inc., Cary, NC, USA.

23. Singh, N.J.; Pandey. R.K. (2010): Thin layer drying kinetics of sweet potato cubes. IE(1) Journal-AG, 91: 24-31.

24. Sokele, E. (1998.): Prijenos topline. Prehrambeno tehnološki fakultet Osijek, Osijek, 1-64.

25. Svihus, B.; Ulhen, A. K.; Harstad, O. M. (2005.): Effect of Starch Granule Structure, Associated Components and Processing on Nutritive Value of Cereal Starch. Animal Feed Science and Technology 122, s. 303-320.

26. Tomas, S. (2000.): Sušenje, apsorpcija. Prehrambeno-tehnološki fakultet Osijek, Osijek, 1-14.

27. Ukom, A.P.; Ojimelukwe, P.C Okpara, D.A. ( 2009.): Nutrient composition of select sweet potato [/pomoea batatas (L. lam)] Varieties as influenced by different level of nitrogen fertilizer application. Pakistan. J. Nutrit. 8 (11) 17911795.

28. Van Hal, M. (2000.): Quality of sweet potato flour during processing and storage. Food Reviews International, 16(1), 1-37.

29. Wang, N.; Brennan, J.G. (1995.): Changes in structure, density and porosity of potato during dehydration. Journal of Food Engineering, 24(1), 61-76

30. Woolfe, J.A. (1992.): Sweetpotato: an untapped food resource. Cambridge: Cambridge University Press, str. 12.

31. Yadav, A.R.; Guha, M.; Tharanathan, R. N.; Ramteke, R S. (2006.): Changes in characteristics of sweet potato flour prepared by different drying techniques. LWT-Food Science and Technology, 39(1), 20-26. 


\section{SUMMARY}

Sweet potato (Ipomoea batatas L.) is a multi-year tropical vegetable culture used in the feeding of domestic animals (cows, pigs and poultry), and in the last couple of years its consumption in human nutrition has increased. The aim of this study is to determine the ash and starch content of the sweet potato, for digestibility, after the convection drying - dehydration at three different drying temperatures $\left(50,60\right.$ and $\left.70^{\circ} \mathrm{C}\right)$, water release drying rate in the drying process as well as the effect of drying temperature on color changes of four different sweet potato varieties, (orange Beauregard, purple 414 Purple, yellow O'Henry and white Japanese). The research results show that of all four investigated varieties only one released water while drying quicker, while all others release water at the same rate. The ash and starch content increased by increasing the temperature. It was also found that drying affected the color change, and the slightest change occured at the lowest temperature as expected. Statistical analysis of the results revealed significant differences between varieties and the thermal finishing method.

Keywords: sweet potato, drying, qualitative characteristics, color change 